\title{
A Benchmarking Strategy for Delhi Transport Corporation: An Application of Data Envelopment Analysis
}

\author{
Punita Saxena \\ Department of Mathematics \\ Shaheed Rajguru College of Applied Sciences for Women \\ University of Delhi, India \\ E-mail: punita.saxena@ rajguru.du.ac.in
}

(Received April 10, 2018; Accepted August 6, 2018)

\begin{abstract}
The growth of any developing economy depends largely on its transport sector. Growing economy leads to more job opportunities and movement of people from rural to urban areas. Public road transport hence plays a significant role as a support system in carrying passengers. This paper discusses the efficiency of State Transport Undertakings of India, in particular, Delhi Transport Corporation (DTC) using the technique of Data Envelopment Analysis (DEA) and regression analysis. A data set of 46 State Transport Undertakings of India have been considered for the study. DEA was applied to compute the efficiencies of units under study. Potential improvements in the input and output variables were computed for the inefficient units. Regression analysis was then performed to identify the explanatory variables that significantly affect the input and output variables. It was observed that DTC is one amongst the worst performers. It showed a technical inefficiency of $50.94 \%$ and was operating on decreasing returns to scale. Further, DTC needs to increase its output substantially in order to attain the level of efficiency. Also it is not utilizing its resources optimally as it needs to reduce all its inputs. In other words, DTC is not utilizing its resources as optimally as its efficient peers. This paper is an attempt to apply regression technique along with the non parametric technique of Data Envelopment Analysis so that the decision makers of DTC can identify the areas where improvement is required and plan a strategy to improve their performance. This would enable DTC to move from a loss incurring to a profit making unit.
\end{abstract}

Keywords- Efficiency evaluation, DEA, Public transport, DTC, Regression analysis.

\section{Introduction}

India, over the past few decades has witnessed a transition from a third world country to a fast growing economy. This swing has been possible due to its shift of Gross Domestic Product (GDP) from agriculture to manufacturing and tertiary sectors. However, the paradigm shift has resulted in the expansion of urban areas across the whole country. With rapid urbanization and more job opportunities, the mobility of people to and from a place of work also grows fast. Thus, residents expect an efficient public road transport system. Delhi, a major metropolis, is officially the National Capital Territory of India. It is the largest city in India in terms of geographical area of 1483 sq.km with a population of 16.75 million. According to the 2011 census, $97.5 \%$ of the population of Delhi lives in urban areas (Delhi Government website). Delhi has expanded its boundaries over the last few years but, unfortunately, the share of road public transport vehicles in the city has declined. The number of private vehicles has seen a sharply increasing trend. This has led to the problem of traffic congestion on the roads resulting in many more problems such as traffic delays, productivity loss, air and noise pollution and waste of energy. Policymakers thus, need to design and implement performance enhancing measures for their urban transport systems that are commensurate with the challenges they face. However, the policies formulated can lead to an effective improvement only if the operators improve their performance. The managers need to identify the reasons of their poor performance in comparison to their peers who are more efficient. 
International Journal of Mathematical, Engineering and Management Sciences

Vol. 4, No. 1, 232-244, 2019

https://dx.doi.org/10.33889/IJMEMS.2019.4.1-020

Efficiency measurement by using the non-parametric technique of Data Envelopment Analysis or DEA, as it is commonly called, has been a topic of great interest for researchers working in this field. DEA, was put forth by Farrell (1957) and extended by Charnes et al. (1978). It was initially used to evaluate and compare the efficiencies of non-profit organizations whose performance cannot be measured on the basis of profits. But, later on, it found its applications in computing the relative efficiency of each decision making unit (DMUs) in comparison with its peers and ranking of these units that have similar set of inputs to produce similar outputs. Public Road Transport Undertakings are one of such congenial units that use an analogous set of inputs and outputs. Various studies have been conducted to evaluate the performance of buses by Levaggi (1994), Cowie and Asenova (1999), Odeck and Alkadi (2001), Pina and Torres (2001), Karlaftis (2003), and Cruz et al. (2012). In India, the State Road Transport Undertakings (SRTUs), owned by the state governments operate the passenger buses for local and interstate commuters. They are the service providers with a social objective. Since the funding for these undertakings come from the government, therefore, it becomes important for researchers to study their performances. For SRTUs of India, similar studies have been carried out by Ramanathan (1999), Jha and Singh (2000), Anjaneyulu et al. (2006), Agarwal et al. (2011), Saxena (2011), Saxena and Saxena (2013), Vaidya (2014), Hanumappa et al. (2015).

Traditional approaches of DEA involve measuring the radial efficiency of each DMU using either the input minimization or the output maximization approach. The objective of these approaches is to compute a factor, namely the efficiency measure so that either inputs can be reduced without changing the outputs or outputs can be increased by keeping the inputs unchanged. However, a measure of efficiency alone is not sufficient for any unit to improve its performance. The underperformers need to identify the areas where improvement is required, analyze how the efficient performers are achieving their high performance levels and then implement in their own organization to improve their performance. In other words, underperformers need to identify their benchmarks and plan a strategy so that they can perk up with the best performing peer units. Dattakumar and Jagadeesh in 2003 defined Benchmarking as a process that compares an organization's performance based on certain parameters in relation to a group of successful peer organizations and providing information on the areas of potential improvements. Basically the intention is to learn from the top performers and adopt best practices for potential improvements. The institutionalization of benchmarking provides operators and policymakers with tools to continuously seek enhanced performance. Benchmarking, therefore, is not only used for the development but also for improving the efficiency of any sector. It provides a road map for performance enhancement. Researchers have recognized the problem of benchmarking as one of the major factors in the process of efficiency improvement. This issue has been studied in various fields such as in public administration by Ammons (2002), production and design by Lee et al. (2011), business management by Tata et al. (2000) and in public passenger transport by Hilmola (2011).

The present paper seeks to meet the following objectives.

- To identify the best performing units and rank all the units in the data set by using DEA.

- To identify the potential improvements in the inputs and outputs for the inefficient units.

- To set the benchmarking targets for the inefficient units.

- To analyze the performance of Delhi Transport Corporation (DTC) in reference to its peers amongst the data set under study.

- To identify the parameters significantly responsible for the improvement of each of the input and the output variable for DTC. 
International Journal of Mathematical, Engineering and Management Sciences

Vol. 4, No. 1, 232-244, 2019

https://dx.doi.org/10.33889/IJMEMS.2019.4.1-020

\section{Models Used}

The frequently used models of DEA are the CCR model given by Charnes et al. (1978) and the BCC model given by Banker et al. (1984). In the CCR model, the frontier is spanned by the linear combination of the units in the data set. The efficiency scores obtained from this model are known as technical efficiencies (TE). These scores reflect the radial distance from the estimated frontier to the unit under consideration. A score less than unity amounts to inefficiency in that unit. The CCR model is based on the assumption of constant returns to scale (CRS).

Mathematically, the CCR model can be described as-

Consider a set of $n$ units, each operating with $m$ inputs and $s$ outputs, let $y_{r j}$ be the amount of the $r^{\text {th }}$ output from unit $j$, and $x_{i j}$ be the amount of the $i^{t h}$ input to the $j^{\text {th }}$ unit. According to the classical DEA model, the relative efficiency of a target unit $j_{0}$ is obtained by maximizing the ratio of the virtual output to virtual input subject to the condition that this ratio is less than unity for all the units of the data set. Thus, the objective is to

$$
\max h_{j_{0}}(u, v)=\frac{\sum_{r=1}^{s} u_{r} y_{r_{0}}}{\sum_{i=1}^{m} v_{i} x_{i j_{0}}}
$$

subject to

$$
\begin{aligned}
& \frac{\sum_{r=1}^{s} u_{r} y_{r j}}{\sum_{i=1}^{m} v_{i} x_{i j}} \leq 1, \quad j=1,2, \ldots ., n \\
& \frac{u_{r_{0}}}{\sum_{i=1}^{m} v_{i} x_{i j}} \geq \varepsilon, \quad r=1,2, \ldots ., s \\
& \frac{v_{i j}}{\sum_{i=1}^{m} v_{i} x_{i j}} \geq \varepsilon, \quad i=1,2, \ldots \ldots . m
\end{aligned}
$$

The decision variables $u=\left(u_{1}, . ., u_{r}, ., u_{s}\right)$ and $v=\left(v_{1}, ., v_{i}, ., v_{m}\right)$ are respectively the weights given to the $s$ outputs and to the $m$ inputs. To obtain the relative efficiencies of all the units, the model is solved $n$ times, for one unit at a time. Model (1) allows for great weight flexibility, as the weights are only restricted by the requirement that they should not be zero (the infinitesimal $\varepsilon$ ensures that) and they should not make the efficiency of any unit greater than one.

The fractional model (1) is solved as a linear program by setting the denominator in the objective function equal to some constant, say, 1 and then maximizing its numerator, as shown in the following model: 
International Journal of Mathematical, Engineering and Management Sciences

Vol. 4, No. 1, 232-244, 2019

https://dx.doi.org/10.33889/IJMEMS.2019.4.1-020

$$
\max h_{j_{0}}=\sum_{r=1}^{s} u_{r} y_{r j_{0}}
$$

subject to

$$
\begin{array}{ll}
\sum_{i=1}^{m} v_{i} x_{i j_{0}}=1 & \\
\sum_{r=1}^{s} u_{r} y_{r j}-\sum_{i=1}^{m} v_{i} x_{i j} \leq 0, & j=1, \ldots, n \\
u_{r}, v_{i} \geq \varepsilon & \forall r, i
\end{array}
$$

Thus, the objective is now to maximize the virtual output of the target unit subject to the condition that virtual output cannot exceed virtual input for every other unit. Technical Efficiencies (TE) are obtained from this model.

DEA is a useful tool for performance improvement through efficiency evaluation and benchmarking. This is done by providing a reference set that consists of efficient units that can be utilized as benchmarks for improvement. The reference set can be obtained by the dual model as shown in (3)

$$
\min z_{j_{0}}=\theta_{j_{0}}-\varepsilon \sum_{r=1}^{s} S_{r j_{0}}{ }^{+}-\varepsilon \sum_{i=1}^{m} S_{i j_{0}}{ }^{-}
$$

subject to

$$
\begin{array}{ll}
\sum_{j=1}^{n} \lambda_{j j_{0}} y_{r j}-S_{r j_{0}}^{+}=y_{r j_{0}}, & r=1,2, \ldots, s \\
\sum \lambda_{j j_{0}} x_{i j}+S_{i j_{0}}^{-}=\theta_{j_{0}} x_{i j_{0}}, & i=1,2, \ldots, m \\
\lambda_{j j_{0}} \geq 0, & j=1,2, \ldots, n \\
\theta_{j_{0}}, \text { unrestricted in sign } & \\
S_{r j_{0}}^{+}, S_{i j_{0}}^{-} \geq 0 \quad r=1,2, \ldots ., s ; i=1,2, \ldots . ., m
\end{array}
$$

By solving model (3), we can identify a linear combination of DMUs (a composite DMU) that utilize less input than the DMU under study while maintaining the same level of outputs. The set of units involved in the construction of the composite DMU are to be treated as benchmarks for improvements of the inefficient DMU under study.

The benchmarks set by efficient units set are the ultimate targets for each inefficient unit in the data set. The slack variables in the above model give the potential improvements needed in the input and the output variables. However, each input or output variable is an agglomeration of various parameters. The decision maker needs to identify the parameter responsible significantly for the variable that needs to improve. Ordinary least square regression technique has been used 
International Journal of Mathematical, Engineering and Management Sciences

Vol. 4, No. 1, 232-244, 2019

https://dx.doi.org/10.33889/IJMEMS.2019.4.1-020

in this paper to help the decision maker of an inefficient unit in identifying the parameter that needs to be worked upon first so that it can reach the efficiency level of its benchmark target.

\section{Methodology}

The data for the present study was obtained from the open government data platform of India that is released under the National Data Sharing and Accessibility Policy (NDSAP). This data was contributed by the Ministry of Road Transport and Highways. In the present paper, data for the year 2014-15 by 46 reporting State Transport Undertakings have been considered. These undertakings are operated either by the government or private agencies.

Technically, the inputs for any study on transport should include the size and quality of the network, spending on investment and maintenance and user inputs such as time, fleet and fuel. Since the availability of the data on the first parameter is difficult to obtain, hence the three variables namely, the Fleet Size (FS), Total Staff (TS) and Total Cost (TC) have been taken as the input variables.

The outcomes on the other hand can be classified into two broad categories namely the desirable or the intended outcomes such as passenger kilometers and the undesirable or the unintended outcomes such as congestion or the accidents. In the present study, the unforeseen outcomes have not been considered and only two variables, namely the passenger-kilometers (PK) and Total revenue (TR) have been taken as the output variables. Variables have been congregated so that the DEA model is able to discriminate between the efficient and inefficient units in the data set under study.

The descriptive statistics of these variables are given in Table 1.

Table 1. Descriptive statistics of variables

\begin{tabular}{|c|c|c|c|c|}
\hline Variables & Maximum & Minimum & Average & Standard Deviation \\
\hline Fleet size & 17957.06 & 33 & 3054.283913 & 3742.076951 \\
\hline Total staff & 107500 & 286 & 16284.84783 & 20771.33745 \\
\hline Total cost & 764967 & 58.08 & 134442.8024 & 167216.6469 \\
\hline Passenger kilometers & 548032.27 & 58.4 & 114154.2179 & 148751.8635 \\
\hline Total revenue & 725866 & 16.77 & 110942.4513 & 147147.4442 \\
\hline
\end{tabular}

Efficiency can be defined as the comparison of actual performance with what can be ideally attained with the same consumption of resources. It relates to the use of all inputs in producing any given output. Thus, it is imperative that the variables categorized as input or output should be correlated. Table 2 below shows that the output and the input variables are strongly correlated. Thus, the cause and effect relationship of the variables was ensured before carrying out further analysis.

Table 2. Correlation between the input and output variables

\begin{tabular}{|c|c|c|c|}
\hline Inputs Output & Fleet Size & Total Staff & Total Cost \\
\hline Passenger kilometers & 0.9044 & 0.8602 & 0.8664 \\
\hline Total revenue & 0.9927 & 0.9634 & 0.9367 \\
\hline
\end{tabular}


International Journal of Mathematical, Engineering and Management Sciences

Vol. 4, No. 1, 232-244, 2019

https://dx.doi.org/10.33889/IJMEMS.2019.4.1-020

DEA models used for analysis fall broadly into two categories, input oriented or output oriented. In the input-oriented model, the configuration is designed to determine how much the input use of a firm could be contracted if used efficiently in order to achieve the same output level. In contrast, with output-oriented DEA, the model is configured to determine a firm's potential output given its inputs if it operated efficiently as firms along the best practicing frontier. Since, the paper deals with the analysis of efficiency scores between the Public Transport Undertakings, and the two output variables are passenger kilometers and total revenue, the output maximizing models of DEA are used for efficiency evaluations.

\section{Results and Discussions}

\subsection{Efficiency Evaluation and Ranking}

Delhi, being the National Capital Territory is one of the important metropolitan cities of India. Over the last few years, the city has witnessed a tremendous growth in the number of private vehicles registered in the city. According to the Transport Department, the number of registered vehicles in Delhi are 1,05,67,712. There are 31,72,842 registered cars and 66,48,730 scooters and motorcycles in the city. The Capital has 2,25,438 goods carriers, 1,18,424 motor cabs, 1,16,092 mopeds, 1,06,082 passenger three-wheelers, 68,692 goods three-wheelers, 35,332 buses, 31,555 e-rickshaws and 30,207 maxi cabs. The population of the city has increased from 13.85 million in 2001 to 26 million in 2015 and 27 million in 2016. Due to non availability of a well organized, proficient public transport system, the number of registered cars and jeeps has steeply increased. The increased use of private cars has resulted in other related problems like traffic congestion, pollution, cases of road rage and accidents multifold. An efficient public transport system in the city would thus solve a lot more related problems as well. It is imperative for the operators of Delhi Transport Corporation to analyse and improve their performance. The managers should look for sustainable solutions so that the commuters reduce the use of private vehicles lest the city will soon choke to death. The present study is an assessment of the performance of DTC. The factors that need to be controlled and improved so that the efficiency of DTC is increased have also been identified.

Out of the 46 units under study, only 6 of them were found to be technically efficient. The average technical efficiency was 0.7571 with that of DTC being 0.38313.In terms of pure technical efficiencies, 14 units were efficient with DTC scoring 0.5095. Also DTC was found to be operating at a decreasing rate of scale with a scale efficiency of 0.7519 . Super efficiencies were computed to rank all the units in the data set. DTC was ranked 39 amongst 46 units under study. Table 3 summarizes the performance of the units under study.

The units under study were classified as efficient, marginally efficient, above average, below average and highly inefficient units by computing the three quartiles of the technical efficiency scores. Six units had a score greater than $\mathrm{Q}_{3}(0.9725)$ that can be called as marginally inefficient unit as they lie very close to the frontier. Eleven units can be called as above average as they had their score lying between $\mathrm{Q}_{2}(0.848)$ and $\mathrm{Q}_{3}$. Similarly, 11 units with scores between $\mathrm{Q}_{1}(0.6301)$ and $\mathrm{Q}_{2}$ can be called below average units and the remaining highly inefficient. These highly inefficient units need special attention as they are the worst performers in this set. DTC happens to be one such unit.

Thus, technically DTC is performing at a very poor level and needs remedial measures that can be applied at the managerial level instead of technology changes. The next step is to look for areas where improvements can be made. 
International Journal of Mathematical, Engineering and Management Sciences

Vol. 4, No. 1, 232-244, 2019

https://dx.doi.org/10.33889/IJMEMS.2019.4.1-020

Table 3. Summary of efficiency scores

\begin{tabular}{|c|c|c|c|c|c|c|}
\hline DMU & CCR Score & BCC Score & $\begin{array}{c}\text { Super } \\
\text { Efficiencies }\end{array}$ & $\begin{array}{c}\text { Scale } \\
\text { Efficiencies }\end{array}$ & Ranking & $\begin{array}{c}\text { Scale of } \\
\text { Operation }\end{array}$ \\
\hline Ahmedabad MTC & 0.372824625 & 0.375646364 & 0.372824625 & 0.99248831 & 40 & Increasing \\
\hline Andhra Pradesh SRTC & 0.94214593 & 1 & 0.94214593 & 0.94214593 & 16 & Decreasing \\
\hline Andaman \& Nicobar ST & 0.345828563 & 0.353930429 & 0.345828563 & 0.977108875 & 41 & Increasing \\
\hline Arunachal Pradesh ST & 0.60400977 & 1 & 0.60400977 & 0.60400977 & 36 & Increasing \\
\hline BEST Undertaking & 0.720770762 & 0.794157612 & 0.720770762 & 0.907591581 & 30 & Decreasing \\
\hline Bangalore Metropolitan TC & 0.97314888 & 0.975462255 & 0.97314888 & 0.997628432 & 12 & Constant \\
\hline Bihar SRTC & 0.626874435 & 0.65338441 & 0.626874435 & 0.959426679 & 35 & Increasing \\
\hline Calcutta STC & 0.307797624 & 0.308497585 & 0.307797624 & 0.997731067 & 42 & Increasing \\
\hline Chandigarh TU & 0.63961244 & 0.658522773 & 0.63961244 & 0.971283706 & 34 & Increasing \\
\hline Delhi TC & 0.383133547 & 0.509497559 & 0.383133547 & 0.751983087 & 39 & Decreasing \\
\hline Gujarat SRTC & 0.970448044 & 0.974817143 & 0.970448044 & 0.995518033 & 13 & Constant \\
\hline Haryana ST & 0.806677517 & 0.834278143 & 0.806677517 & 0.966916758 & 26 & Decreasing \\
\hline Himachal RTC & 0.873920893 & 0.874552701 & 0.873920893 & 0.999277564 & 22 & Increasing \\
\hline J\&K SRTC & 0.600997851 & 0.601004005 & 0.600997851 & 0.999989759 & 37 & Increasing \\
\hline Kadamba TC Ltd. & 0.857363543 & 0.864445196 & 0.857363543 & 0.991807863 & 23 & Increasing \\
\hline Karnataka SRTC & 1 & 1 & 1.017286481 & 1 & 6 & Constant \\
\hline Kerala SRTC & 0.753728135 & 0.756342059 & 0.753728135 & 0.996543992 & 29 & Decreasing \\
\hline Maharashtra SRTC & 0.989226584 & 1 & 0.989226584 & 0.989226584 & 9 & Decreasing \\
\hline Meghalaya STC & 0.829315171 & 1 & 0.829315171 & 0.829315171 & 25 & Increasing \\
\hline Metro TC (Chennai) Limited & 0.899073964 & 0.899395234 & 0.899073964 & 0.999642793 & 21 & Increasing \\
\hline Mizoram ST & 0.117766593 & 1 & 0.117766593 & 0.117766593 & 46 & Increasing \\
\hline Nagaland ST & 0.259937095 & 0.270914424 & 0.259937095 & 0.959480453 & 44 & Increasing \\
\hline Navi Mumbai MT & 0.691197923 & 0.714909305 & 0.691197923 & 0.966833021 & 32 & Increasing \\
\hline North Bengal STC & 0.475151206 & 0.476585735 & 0.475151206 & 0.996989987 & 38 & Increasing \\
\hline North Eastern Karnataka RTC & 0.98945451 & 0.996186742 & 0.98945451 & 0.993241998 & 8 & Constant \\
\hline $\begin{array}{lll}\text { North } & \text { Western } & \text { Karnataka } \\
\text { RTC } & & \\
\end{array}$ & 0.989682368 & 0.98981996 & 0.989682368 & 0.999860993 & 7 & Increasing \\
\hline Odisha SRTC & 1 & 1 & 2.520369564 & 1 & 1 & Constant \\
\hline Pepsu RTC & 0.990733187 & 1 & 0.990733187 & 0.990733187 & 6 & Increasing \\
\hline Pune Mahamandal & 0.838667459 & 0.842008665 & 0.838667459 & 0.996031863 & 24 & Increasing \\
\hline PUNBUS & 1 & 1 & 1.123446856 & 1 & 3 & Constant \\
\hline State Transport Punjab & 0.700869792 & 0.711637922 & 0.700869792 & 0.984868527 & 31 & Increasing \\
\hline Rajasthan SRTC & 0.921627727 & 0.961755227 & 0.921627727 & 0.958276806 & 19 & Decreasing \\
\hline Sikkim NT & 0.796896824 & 1 & 0.796896824 & 0.796896824 & 28 & Increasing \\
\hline Solapur MT & 0.303585644 & 0.407380628 & 0.303585644 & 0.745213746 & 43 & Increasing \\
\hline South Bengal STC & 0.801193892 & 0.807955169 & 0.801193892 & 0.991631618 & 27 & Increasing \\
\hline State Exp.TC TN Ltd. & 1 & 1 & 1.301338062 & 1 & 2 & Constant \\
\hline $\begin{array}{l}\text { Telangana SRTC } \\
\end{array}$ & 0.946707429 & 0.977845693 & 0.946707429 & 0.96815626 & 15 & Decreasing \\
\hline Thane MT & 0.655058127 & 0.670740297 & 0.655058127 & 0.97661961 & 33 & Increasing \\
\hline TN STC (Coimbatore) Ltd. & 0.903430542 & 0.921281781 & 0.903430542 & 0.980623475 & 20 & Constant \\
\hline TN STC (Kumbakonam) Ltd. & 0.976555107 & 0.976661212 & 0.976555107 & 0.99989136 & 11 & Increasing \\
\hline TN STC (Madurai) Ltd. & 0.957816264 & 0.958080755 & 0.957816264 & 0.999723937 & 14 & Constant \\
\hline TN STC (Salem) Ltd. & 0.933502262 & 0.93882242 & 0.933502262 & 0.994333158 & 17 & Increasing \\
\hline TN STC (Villupuram) Ltd. & 1 & 1 & 1.098331591 & 1 & 4 & Constant \\
\hline Tripura RTC & 0.145647273 & 1 & 0.145647273 & 0.145647273 & 45 & Increasing \\
\hline Uttar Pradesh SRTC & 1 & 1 & 1.043386298 & 1 & 5 & Constant \\
\hline Uttarakhand TC & 0.93306807 & 0.937541671 & 0.93306807 & 0.99522837 & 18 & Increasing \\
\hline
\end{tabular}


International Journal of Mathematical, Engineering and Management Sciences

Vol. 4, No. 1, 232-244, 2019

https://dx.doi.org/10.33889/IJMEMS.2019.4.1-020

\subsection{Potential Improvements}

- The slack variables in the DEA model (3) give the potential improvements needed in the variables so that an inefficient unit can elevate itself to an efficient unit. These potential improvements in the value of outputs for inefficient units were also studied. Since the model used was the output oriented model, therefore, the inefficient units need to improve their efficiency scores by increasing their level of outputs without changing their level of inputs.

Table 4. Potential improvements (in percentage)

\begin{tabular}{|c|c|c|c|c|c|}
\hline DMU & Fleet Size & Staff & Total Cost & Passenger Km & Total Revenue \\
\hline Ahmedabad MTC & $0.00 \%$ & $-19.16 \%$ & $0.00 \%$ & $168.22 \%$ & $168.22 \%$ \\
\hline Andhra Pradesh SRTC & $0.00 \%$ & $0.00 \%$ & $0.00 \%$ & $20.95 \%$ & $6.14 \%$ \\
\hline Andaman \& Nicobar ST & $-3.80 \%$ & $-59.47 \%$ & $0.00 \%$ & $999.90 \%$ & $189.16 \%$ \\
\hline Arunachal Pradesh ST & $-98.58 \%$ & $-99.48 \%$ & $0.00 \%$ & $65.56 \%$ & $267.61 \%$ \\
\hline BEST Undertaking & $0.00 \%$ & $-24.07 \%$ & $0.00 \%$ & $274.25 \%$ & $38.74 \%$ \\
\hline Bangalore Metropolitan TC & $0.00 \%$ & $-45.47 \%$ & $0.00 \%$ & $2.76 \%$ & $2.76 \%$ \\
\hline Bihar SRTC & $-44.01 \%$ & $-77.35 \%$ & $0.00 \%$ & $107.76 \%$ & $59.52 \%$ \\
\hline Calcutta STC & $0.00 \%$ & $-65.10 \%$ & $0.00 \%$ & $224.89 \%$ & $224.89 \%$ \\
\hline Chandigarh TU & $0.00 \%$ & $0.00 \%$ & $0.00 \%$ & $56.34 \%$ & $56.34 \%$ \\
\hline Delhi TC & $0.00 \%$ & $-3.94 \%$ & $-32.27 \%$ & $161.01 \%$ & $161.01 \%$ \\
\hline Gujarat SRTC & $0.00 \%$ & $-12.53 \%$ & $0.00 \%$ & $3.05 \%$ & $3.05 \%$ \\
\hline Haryana ST & $0.00 \%$ & $0.00 \%$ & $0.00 \%$ & $23.97 \%$ & $23.97 \%$ \\
\hline Himachal RTC & $0.00 \%$ & $0.00 \%$ & $0.00 \%$ & $999.90 \%$ & $14.43 \%$ \\
\hline J\&K SRTC & $-27.03 \%$ & $-64.84 \%$ & $0.00 \%$ & $226.58 \%$ & $66.39 \%$ \\
\hline Kadamba TC Ltd. & $0.00 \%$ & $-42.78 \%$ & $0.00 \%$ & $16.64 \%$ & $16.64 \%$ \\
\hline Karnataka SRTC & $0.00 \%$ & $0.00 \%$ & $0.00 \%$ & $0.00 \%$ & $0.00 \%$ \\
\hline Kerala SRTC & $0.00 \%$ & $-22.32 \%$ & $0.00 \%$ & $999.90 \%$ & $32.67 \%$ \\
\hline Maharashtra SRTC & $0.00 \%$ & $-14.88 \%$ & $0.00 \%$ & $90.36 \%$ & $1.09 \%$ \\
\hline Meghalaya STC & $0.00 \%$ & $-66.38 \%$ & $0.00 \%$ & $478.30 \%$ & $20.58 \%$ \\
\hline Metro TC (Chennai) Limited & $0.00 \%$ & $-24.52 \%$ & $0.00 \%$ & $11.23 \%$ & $11.23 \%$ \\
\hline Mizoram ST & $0.00 \%$ & $-49.96 \%$ & $-1.31 \%$ & $911.61 \%$ & $749.14 \%$ \\
\hline Nagaland ST & $0.00 \%$ & $-63.34 \%$ & $0.00 \%$ & $284.71 \%$ & $284.71 \%$ \\
\hline Navi Mumbai MT & $0.00 \%$ & $-39.37 \%$ & $0.00 \%$ & $999.90 \%$ & $44.68 \%$ \\
\hline North Bengal STC & $0.00 \%$ & $-51.85 \%$ & $0.00 \%$ & $110.46 \%$ & $110.46 \%$ \\
\hline North Eastern Karnataka RTC & $0.00 \%$ & $-28.10 \%$ & $0.00 \%$ & $1.07 \%$ & $1.07 \%$ \\
\hline North Western Karnataka RTC & $0.00 \%$ & $-25.02 \%$ & $0.00 \%$ & $1.04 \%$ & $1.04 \%$ \\
\hline Odisha SRTC & $0.00 \%$ & $0.00 \%$ & $0.00 \%$ & $0.00 \%$ & $0.00 \%$ \\
\hline Pepsu RTC & $0.00 \%$ & $0.00 \%$ & $-0.50 \%$ & $999.90 \%$ & $0.94 \%$ \\
\hline Pune Mahamandal & $0.00 \%$ & $0.00 \%$ & $0.00 \%$ & $113.92 \%$ & $19.24 \%$ \\
\hline PUNBUS & $0.00 \%$ & $0.00 \%$ & $0.00 \%$ & $0.00 \%$ & $0.00 \%$ \\
\hline State Transport Punjab & $0.00 \%$ & $-37.25 \%$ & $0.00 \%$ & $999.90 \%$ & $42.68 \%$ \\
\hline Rajasthan SRTC & $0.00 \%$ & $0.00 \%$ & $0.00 \%$ & $8.50 \%$ & $8.50 \%$ \\
\hline Sikkim NT & $0.00 \%$ & $-30.39 \%$ & $0.00 \%$ & $999.90 \%$ & $25.49 \%$ \\
\hline Solapur MT & $0.00 \%$ & $0.00 \%$ & $0.00 \%$ & $999.90 \%$ & $229.40 \%$ \\
\hline South Bengal STC & $0.00 \%$ & $-14.07 \%$ & $0.00 \%$ & $24.81 \%$ & $24.81 \%$ \\
\hline State Exp.TC TN Ltd. & $0.00 \%$ & $0.00 \%$ & $0.00 \%$ & $0.00 \%$ & $0.00 \%$ \\
\hline Telangana SRTC & $0.00 \%$ & $-7.47 \%$ & $0.00 \%$ & $30.79 \%$ & $5.63 \%$ \\
\hline Thane MT & $0.00 \%$ & $-66.93 \%$ & $0.00 \%$ & $120.09 \%$ & $52.66 \%$ \\
\hline TN STC (Coimbatore) Ltd. & $0.00 \%$ & $0.00 \%$ & $-1.45 \%$ & $10.69 \%$ & $10.69 \%$ \\
\hline TN STC (Kumbakonam) Ltd. & $0.00 \%$ & $-1.10 \%$ & $0.00 \%$ & $4.45 \%$ & $2.40 \%$ \\
\hline TN STC (Madurai) Ltd. & $0.00 \%$ & $0.00 \%$ & $0.00 \%$ & $4.40 \%$ & $4.40 \%$ \\
\hline TN STC (Salem) Ltd. & $0.00 \%$ & $-0.40 \%$ & $-5.07 \%$ & $7.12 \%$ & $12.74 \%$ \\
\hline TN STC (Villupuram) Ltd. & $0.00 \%$ & $0.00 \%$ & $0.00 \%$ & $0.00 \%$ & $0.00 \%$ \\
\hline Tripura RTC & $0.00 \%$ & $-53.68 \%$ & $0.00 \%$ & $586.59 \%$ & $586.59 \%$ \\
\hline Uttar Pradesh SRTC & $0.00 \%$ & $0.00 \%$ & $0.00 \%$ & $0.00 \%$ & $0.00 \%$ \\
\hline Uttarakhand TC & $0.00 \%$ & $-37.75 \%$ & $0.00 \%$ & $999.90 \%$ & $7.17 \%$ \\
\hline
\end{tabular}


International Journal of Mathematical, Engineering and Management Sciences

Vol. 4, No. 1, 232-244, 2019

https://dx.doi.org/10.33889/IJMEMS.2019.4.1-020

- For most of the units it was observed that they not only need to improve their outputs but also need to decrease their inputs so as to reach the efficiency level as per their peers. Among these units they all need to decrease their staff. A few of them need to decrease their fleet size also. This means that the Undertakings have enough fleet size to provide better services and earn revenues but an improper management of infrastructure leads to inefficiency.

- DTC was observed to be the only unit that needs to decrease its cost by around $32 \%$. It needs to decrease its staff by approximately $4 \%$ and increase its revenue and passenger kilometers by $161 \%$ each. Table 4 depicts the potential improvements in various inputs and outputs required by the inefficient units.

The analysis reflected that DTC needs a radical improvement in the output variables. Table 4 further shows that the highly inefficient units like DTC also need to reduce their input variables like Staff and fleet size. The only units in the data set that needs to reduce their cost are DTC and Mizoram. Since variables were congregated to encompass only five variables for the study, therefore exploratory analysis was done to identify the factors that significantly affect these variables. Multiple regression analysis was used for this purpose.

\subsection{Regression Analysis for Input Variables}

DTC was the only unit in the data set that required a reduction in its total cost. Thus, the factors responsible for total cost were explored. Explanatory variables for total cost were identified as cost $/ \mathrm{km}$, cost/bus/day, staff costs, fuel and lubricants cost, cost of tires and tubes, cost of spares, taxes and other costs. A linear relationship between them was studied and summarized in Table 5 . It was observed that variables like cost $/ \mathrm{km}$, cost/bus/day, cost of tires and tubes, the cost of spares and Taxes paid had a p-value for their coefficients greater than 0.05 . Thus, they can be neglected for further study. However, factors like staff costs, fuel and lubricants cost and other costs are ones that had the smallest $p$-values. These variables can be considered to be the ones that need to be controlled on first priority. Reducing these factors would lead to a reduction in the value of the variable of total cost and hence an improvement in the efficiency level of DTC.

Table 5. Regression analysis for total cost

\begin{tabular}{|l|c|c|c|c|}
\hline & Coefficients & Standard Error & $\boldsymbol{t}$ Stat & P-Value \\
\hline Intercept & -27434.94619 & 13793.41055 & -1.988989314 & 0.054134972 \\
\hline Cost/KM & -0.110489674 & 0.99083929 & -0.111511196 & 0.911813731 \\
\hline Cost/Bus/Day & 2.885799518 & 1.569053484 & 1.839197674 & 0.073921556 \\
\hline Staff Costs & 1.611231175 & 0.274526932 & 5.8691188 & $\mathbf{9 . 4 4 3 5 2 E - 0 7}$ \\
\hline Fuel and Lubricants Cost & 1.342046065 & 0.522977486 & 2.566164131 & $\mathbf{0 . 0 1 4 4 6 5 9 9 5}$ \\
\hline Cost of Tyers\& Tubes & -9.524045565 & 6.22902284 & -1.528979073 & 0.134774793 \\
\hline Cost of Spares & -5.098364806 & 2.944690731 & -1.731375303 & 0.091716728 \\
\hline Taxes & 1.390933885 & 0.759843186 & 1.83055387 & 0.075231011 \\
\hline Other Cost & 1.746136918 & 0.435078618 & 4.013382513 & $\mathbf{0 . 0 0 0 2 8 0 3 0 8}$ \\
\hline
\end{tabular}

It was observed that DTC needs to reduce its total staff by $3.94 \%$. The possible explanatory factors for this variable were Staff/Bus ratio and staff productivity. Though the reduction required in this input variable is not high, still regression analysis was performed to test if any significant explanatory factors could be identified for this variable. Table 6 summarizes this analysis. The pvalue for the regression analysis was 0.11845 indicating that this variable is not significantly affecting the performance of DTC. 
International Journal of Mathematical, Engineering and Management Sciences

Vol. 4, No. 1, 232-244, 2019

https://dx.doi.org/10.33889/IJMEMS.2019.4.1-020

Table 6. Regression analysis for total staff

\begin{tabular}{|l|c|c|c|c|}
\hline & Coefficients & Standard Error & $\boldsymbol{t}$ Stat & $\boldsymbol{P}$-Value \\
\hline Intercept & -9614.83 & 13314.73982 & -0.72212 & 0.474129988 \\
\hline Staff/Bus Ratio & 2729.486 & 1698.424309 & 1.60707 & 0.115358433 \\
\hline Staff Productivity (Kms/Staff/Day) & 223.3013 & 110.5518255 & 2.019879 & 0.049654839 \\
\hline
\end{tabular}

The table for potential improvements shows that DTC need not reduce its fleet size. But, the cost incurred by the unit is also dependent on the fleet size. Thus, regression analysis was performed for this variable also as summarized in Table 7. Factors like fleet utilization, over aged vehicles, number of accidents and the average age of the fleet were considered as the explanatory variables. Number of accidents was considered because due to accidents, the buses may not be on the roads thus affecting the performance of the unit. The p-values reflected that factors like fleet utilization, over aged vehicles and number of accidents significantly affect the input variable of fleet size. Thus, it substantiates the fact that the cost being incurred on spares is significantly contributing to the total cost because fleet of DTC is more in workshops than on roads. Hence, DTC needs to manage and maintain its buses properly on a regular basis. Simply replacing the existing buses will not be very helpful unless a policy decision on operations is made as else the same condition will be repeated after a few years.

Table 7. Regression analysis for fleet size

\begin{tabular}{|l|c|c|c|c|}
\hline & Coefficients & Standard Error & t Stat & \multicolumn{1}{c|}{ P-Value } \\
\hline Intercept & -2646.08 & 1689.521 & -1.56617 & 0.124995438 \\
\hline Fleet Utilisation (\%) & 39.20929 & 17.80665 & 2.201947 & $\mathbf{0 . 0 3 3 3 5 1 8 0 3}$ \\
\hline Over aged vehicles (\%) & -32.4864 & 12.87461 & -2.52329 & $\mathbf{0 . 0 1 5 5 9 7 9 6 6}$ \\
\hline Number of Accidents & 5.062001 & 0.532215 & 9.511193 & $\mathbf{6 . 2 5 4 7 4 E - 1 2}$ \\
\hline Avg. Age of Fleet & 222.9557 & 161.0254 & 1.3846 & 0.173664349 \\
\hline
\end{tabular}

\subsection{Regression Analysis for Output Variables}

DTC needs a substantial increase of $161.01 \%$ both in total revenue and in passenger kilometers. This is practically very difficult to attain. Thus, it was felt that they need to identify the factors that are significantly responsible for these variables. Regression analysis was performed to identify the statistically significant explanatory variables for both the output variables. Tables 8 and 9 summarize the regression analysis for both the output variables.

Table 8. Regression analysis for total revenue

\begin{tabular}{|c|c|c|c|c|}
\hline & Coefficients & Standard Error & $t$ Stat & P-Value \\
\hline Intercept & 79275.12522 & 25680.18604 & 3.087015 & 0.003712543 \\
\hline Revenue/Km & -0.04087246 & 1.718152216 & -0.02379 & 0.981142524 \\
\hline Revenue/Bus/Day & 2.419807506 & 1.468020583 & 1.648347 & 0.107315561 \\
\hline Revenue Earning Kilometres & 32.44732068 & 0.89503837 & 36.25244 & 1.18472E-31 \\
\hline Profit/Loss per Km & -1.398533617 & 1.261233256 & -1.10886 & 0.274281021 \\
\hline Profit/Loss per Bus/Day & 2.539183135 & 1.68125736 & 1.510288 & 0.139030369 \\
\hline Fuel Efficiency & -22403.47667 & 6029.401814 & -3.7157 & 0.000634112 \\
\hline
\end{tabular}


International Journal of Mathematical, Engineering and Management Sciences

Vol. 4, No. 1, 232-244, 2019

https://dx.doi.org/10.33889/IJMEMS.2019.4.1-020

Table 9. Regression analysis for passenger kilometers

\begin{tabular}{|l|c|c|c|c|}
\hline & Coefficients & Standard Error & t Stat & P-Value \\
\hline Intercept & 43967.82278 & 20009.66533 & 2.197329 & 0.033703643 \\
\hline Passenger Kms Performed (Lakhs) & 1.432376506 & 0.04586161 & 31.23258 & $3.29618 \mathrm{E}-30$ \\
\hline Occupancy Ratio (\%) & -498.6062381 & 249.7014331 & -1.99681 & 0.052513628 \\
\hline Passenger Carried (Lakh) & 2.378964762 & 1.075973021 & 2.210989 & 0.032672226 \\
\hline Passengers carried per Bus/Day (Number) & -50.45350492 & 17.04217985 & -2.96051 & 0.005086841 \\
\hline
\end{tabular}

Six explanatory variables were identified for the output of total revenue. Total revenue was regressed with Revenue/km, revenue/bus/day, revenue earning kilometers, profit/loss per km, profit/loss/bus/day and fuel efficiency. Table 8 shows that only revenue earning kilometers and fuel efficiency are statistically significant. Fuel efficiency is a factor that should be seriously taken by the managers. Controlling it will not only improve the revenue of the unit but will also reduce the depletion of natural resources. The managers should take special care while framing the policies for operations and route scheduling. The traffic congestion leads to traffic jams. Buses get held up in these jams and hence fuel efficiency gets affected. One of the options that policy makers can consider is to operate the buses on short trips in loops having good connectivity with each loop. This would increase the punctuality of the buses and also the buses won't miss their trips which they do if they are stuck in traffic jams. In this manner revenue earning kilometers will also improve thus improving the total revenue.

Table 9 shows that both passenger kilometers performed and passenger carried are significant for the output variables of passenger kilometers. This means that in the present state, buses are not performing the trips they should have performed. In other words, demand is more than the supply leading to poor performance of DTC. Occupancy ratio is a significant factor specially because of increasing number of private vehicles in Delhi.

The managers and policy makers of DTC need to look for alternatives and remedial measures so that they improve their efficiencies and move from loss incurring units to profit making organization. Since it's a government funded unit, the city is bearing the finances of this unit which otherwise could be used for other developments.

\section{Conclusions}

This paper is an attempt to evaluate the efficiencies of State Transport Undertakings of India with a special reference to DTC for the year 2015-16. The results show that DTC is one of the worst performing undertakings that needs special attention. It needs to increase its revenue and passenger kilometers offered by $161 \%$ to be able to reach the frontiers as created by its peers. Further, it also needs to decrease its total cost by $32.27 \%$ and staff by $3.94 \%$. The study carried out suggests that the need of the hour is to improve the operations and maintenance of the fleet used by DTC. The decision makers should plan and execute policies that are beneficial for the end users and operators both. Scheduling of buses should be done to meet the demands of the commuters. Vehicle density and punctuality should be the basis for deciding the routes of the buses. Short trips by buses in small loops will yield better results compared to long routes point to point buses. In case DTC is able to improve its passenger kilometers offered, total revenue earned will also improve. Hence, there is a vast scope for DTC to improve its efficiency by optimally utilizing and managing its resources. The goals of the operators are to meet the social objectives of providing quality public transport to the citizens and to generate revenue for the government. 
International Journal of Mathematical, Engineering and Management Sciences

Vol. 4, No. 1, 232-244, 2019

https://dx.doi.org/10.33889/IJMEMS.2019.4.1-020

The study shows that DTC is not able to meet either of them. The commuters are not getting the desired quality services and the unit is working as a loss incurring sector. Infrastructural changes like replacing the old fleets alone will not be sufficient to improve the efficiency of the unit. The impact of these changes will be visible only with competent planning and effective implementation.

\section{Conflict of Interest}

The author confirms that there is no conflict of interest to declare for this publication.

\section{Acknowledgement}

The author would like to express her sincere thanks to the referee/s for their valuable suggestions towards to the improvement of the paper.

\section{References}

Agarwal, S., Yadav, S. P., \& Singh, S. (2011). DEA based estimation of the technical efficiency of state transport undertakings in India. Opsearch, 47(3), 216-230.

Ammons, D. N. (2002). Benchmarking as a performance management tool: Experiences among municipalities in North Carolina. European Journal of Operational Research, 140, $249-265$.

Anjaneyulu, M. V. L. R., Nagraj, B. N., \& Chandrashekhar, S. (2006). DEA approach for performance analysis of state road transport undertakings. Indian Journal of Transport Management, 30(4), 392409.

Banker, R. D., Charnes, A., \& Cooper, W. W. (1984). Some models for estimating technical and scale inefficiencies in data envelopment analysis. Management Science, 30(9), 1078-1092.

Charnes, A., Cooper, W. W., \& Rhodes, E. (1978). Measuring the efficiency of decision making units. European Journal of Operational Research, 2(6), 429-444.

Cowie, J., \& Asenova, D. (1999). Organisation form, scale effects and efficiency in the bus industry. Transportation, 26(3), 231-248.

Cruz, L., Barata, E., \& Ferreira, J. (2012). Performance in urban public transport systems: A critical analysis of the Portugese case. International Journal of Productivity and Performance Management, 61(7), 730-751.

Dattakumar, R., \& Jagadeesh, R. (2003). A review of literature on benchmarking. Benchmarking: An International Journal, 10(3), 176-209.

Farrell, M. J. (1957). The measurement of productive efficiency. Journal of the Royal Statistical Society, Series A (General), 120(3), 253-290.

Hanumappa, D., Ramachandaran, P., Sitharam, T., \& Lakshmana, S. (2015). Performance evaluation of Bangalore metropolitan transport coordination: an application of data envelopment analysis. Journal of Public Transportation, 18(2), 1-19.

Hilmola, O. P. (2011). Benchmarking efficiency of public passenger transport in larger cities. Benchmarking: An International Journal, 18(1), 23-41.

Jha, R., \& Singh, S. K. (2000). Small is efficient: a frontier approach to cost inefficiencies in Indian state transport undertakings. International Journal of Transport Economics, 28(1), 95-114. 
International Journal of Mathematical, Engineering and Management Sciences

Vol. 4, No. 1, 232-244, 2019

https://dx.doi.org/10.33889/IJMEMS.2019.4.1-020

Karlaftis, M. G. (2003). Investigating transit production and performance: a programming approach. Transportation Research Part A: Policy Practice, 37(3), 225-240.

Lee, S., Ryu, K., Bae, H., \& Park, Y. (2011). A framework for evaluating reconfigurability of collaboration system using DEA. ICIC Express Letters, 5(5), 1673-1678.

Levaggi, R. (1994). Parameteric and non parametric approaches to efficiency: the case of urban transit in Italy. Economic Studies, 21(53), 67-88.

Odeck, J., \& Alkadi, A. (2001). Evaluating efficiency in Norwegian bus industry using data envelopment analysis. Transportation, 28(3), 211-232.

Pina, V., \& Torres, L. (2001). Analysis of the efficiency of the local government services delivery: an application to urban public transport. Transport Research. Part A: Policy Practice, 35(10), 929-944.

Ramanathan, R. (1999). Using data envelopment analysis for assessing the productivity of state road transport undertakings. Indian Journal of Transport Management, 23(5), 301-312.

Saxena, P., \& Saxena, R. R. (2011). Measuring efficiencies in Indian Public Road Transit: a data envelopment analysis approach. Opsearch, 47(3), 195-204.

Saxena, P. (2013). Comparing the efficiencies of state transport undertakings using data envelopment analysis. International Journal of Mathematics and Computer Applications Research, 3(5), 89-100.

Tata, J., Prasad, S., \& Motwani, J. (2000). Benchmarking quality management practices: US versus Costa Rica. Multinational Business Review, 8(2), 37.

Transforming city bus transport in India through financial assistance for bus procurement under JnNURM. Ministry of Urban Development.

Vaidya, O. S. (2014). Evaluating the performance of public urban transportation systems in India. Journal of Public Transportation, 17(4), 174-191.

Links:

www.data.gov.in/catalog/

www.delhi.gov.in, Economic Survey of Delhi, 2012-13. 